\title{
Synthesis, theoretical studies, and effect on the photosynthetic electron transport of trifluoromethyl arylamides
}

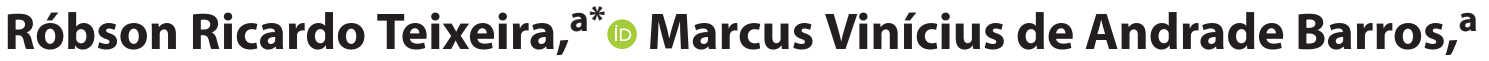 \\ Gustavo Costa Bressan, ${ }^{b}$ Raoni Pais Siqueira, ${ }^{b}$ Fabíola Suelen dos Santos, ${ }^{a}$ \\ Michele Bertazzini, ${ }^{\mathrm{C}}$ Rudolf Kiralj, ${ }^{\mathrm{d}}$ Márcia Miguel Castro Ferreira ${ }^{\mathrm{e}}$ \\ and Giuseppe Forlani ${ }^{*}$
}

\section{Abstract}

BACKGROUND: The photosynthetic apparatus is targeted by various herbicides, including several amides such as diuron and linuron. Considering the need for the discovery of new active ingredients to cope with weed resistance, the synthesis of a series of trifluoromethyl aryl amides is herein described whose inhibitory properties were assessed in vitro on the photosynthetic electron transport chain, and in vivo on the growth of a model cyanobacterial strain. Theoretical studies were also carried out.

\begin{abstract}
RESULTS: Starting with 1-fluoro-2-nitro-4-(trifluoromethyl) benzene, the preparation of the amides was achieved via a three-step sequence, namely nucleophilic aromatic substitution, reduction with $\mathrm{SnCl}_{2} / \mathrm{HCl}$, and acylation reactions. The measurement of ferricyanide reduction by functionally intact spinach chloroplasts showed that several derivatives are capable of inhibiting the photosynthetic apparatus. The most active amides presented IC 50 values close to $1 \mu \mathrm{mol} \mathrm{L}^{-1}$, and showed the presence of a 4-bromophenyl group as a common structural feature. The addition of these brominated amides to the culture medium of a model cyanobacterial strain, Synechococcus elongatus PCC 6301, caused various degrees of growth inhibition. Theoretical studies (molecular modeling and quantitative structure-activity relationship) of all amides and their comparison with some known herbicides confirmed these experimental findings and provided more in-depth information about the possible molecular target of these compounds.
\end{abstract}

CONCLUSION: Trifluoromethyl amides herein described, which were shown to act at the PSII level, may represent a novel scaffold to be exploited aiming at the development of new active ingredients for weed control.

(c) 2017 Society of Chemical Industry

Supporting information may be found in the online version of this article.

Keywords: trifluoromethyl aryl amides; herbicides; photosynthetic electron transport; quantitative structure-activity relationship

\section{INTRODUCTION}

During photosynthesis, a complex series of electron transfer reactions allows higher plants, algae and certain bacteria to convert sunlight into chemical energy. ${ }^{1-3}$ A variety of compounds are capable of interfering with the photosynthetic electron transport. ${ }^{4-7}$ This fact has been early explored by agrochemical companies to develop an assortment of herbicides to control weeds, some of which are shown in Fig. 1. Photosynthesis inhibitors act mainly by blocking the electron transport at the photosystem II level, or through diversion of the electron flow at the photosystem I level. ${ }^{8}$

The ability of crops to survive their application usually relies upon the presence of detoxifying enzymes. However, because of a high selective pressure for weeds, a rapid diffusion of resistant biotypes usually occurs within a few years after herbicide introduction, dramatically reducing the commercial life of most active principles. As a consequence, there is a constant need for the discovery of new active scaffolds to manage weed resistance.
As can be noticed in Fig. 1, several inhibitors of the photosynthetic process have an amide group in their structure. In fact,

\footnotetext{
Correspondence to: RR Teixeira, Departamento de Química, Universidade Federal de Viçosa, Av. P. H. Rolfs, S/N, Viçosa, MG, 36.570-900, Brazil. E-mail: robsonr.teixeira@ufv.br; or G Forlani, Department of Life Science and Biotechnology, University of Ferrara, via L. Borsari 46, I-44121 Ferrara, Italy. E-mail: flg@unife.it

a Departamento de Bioquímica e Biologia Molecular, Universidade Federal de Viçosa, Viçosa, MG, Brazil

b Departamento de Bioquímica e Biologia Molecular, Viçosa, MG, Brazil

c Department of Life Science and Biotechnology, University of Ferrara, Ferrara, Italy

d Technical College in Bjelovar, Trg E. Kvaternika 4, Bjelovar, Croatia

e Instituto de Química, Universidade Estadual de Campinas, Campinas, SP, Brazil
} 
<smiles>CN(C)C(=O)Nc1ccc(Cl)c(Cl)c1</smiles><smiles>CN(C)c1nc(=O)n(C2CCCCC2)c(=O)[nH]1</smiles>

Hexazinone<smiles>CCC(=O)Nc1ccc(Cl)c(Cl)c1</smiles>

Propanil<smiles>CCNc1nc(Cl)nc(NC(C)C)n1</smiles>

Atrazine<smiles>CCOC(=O)Nc1cccc(OC(=O)CNc2ccccc2)c1</smiles>

Desmedipham

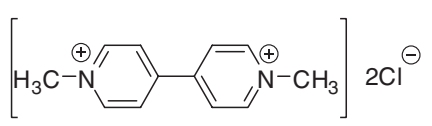

Paraquat<smiles>O=c1[nH]c2c(c(=O)n1C1CCCCC1)CCC2</smiles>

Lenacil<smiles>N#Cc1cc(Br)c(O)c(Br)c1</smiles>

Bromoxynil

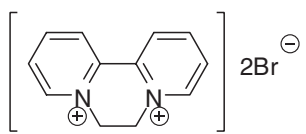

Diquat

Figure 1. Examples of commercial herbicides that inhibit photosynthesis.

the presence of this functionality or a carbamate group is a common structural feature among herbicides targeting the photosynthetic apparatus. ${ }^{9,10}$ Within this context, we describe in this paper the synthesis of a series of trifluoromethyl aryl amides whose inhibitory properties were assessed in vitro on the photosynthetic electron transport chain, and in vivo on the growth of a model cyanobacterial strain. In addition, theoretical studies (molecular modeling and quantitative structure-activity relationship) of aryl amides were carried out, and the results were compared with experimental findings, chemical knowledge, and relevant literature.

\section{MATERIALS AND METHODS}

\subsection{General procedures}

Analytical grade 1-fluoro-2-nitro-4-trifluoromethyl benzene, piperidine, morpholine, cyclohexylamine, diethylamine, 4-bromoaniline, pyrrolidine, isonicotinoyl chloride hydrochloride, nicotinoyl chloride hydrochloride, 2-chloropyridine-3-carboxylic acid and benzoyl chloride were purchased from Sigma-Aldrich (St. Louis, MO, USA) and used without further purification. Anhydrous tin(II) chloride and triethylamine were purchased from Vetec (Rio de Janeiro, Brazil) and used as received. ${ }^{1} \mathrm{H}$ NMR and ${ }^{13} \mathrm{C}$ NMR spectra were recorded on a Varian Mercury 300 instrument (Varian, Palo Alto, CA, USA) at $300 \mathrm{MHz}$ and $75 \mathrm{MHz}$, respectively, using $\mathrm{CDCl}_{3}$ and $\mathrm{CD}_{3} \mathrm{OD}$ as solvents. Infrared spectra were recorded on either a Varian 660-IR, equipped with GladiATR scanning from 4000 to $500 \mathrm{~cm}^{-1}$ or a Perkin Elmer Paragon 1000 FTIR spectrophotometer (Perkin Elmer do Brasil Ltda, São Paulo, Brazil), using potassium bromide $(1 \% \mathrm{v} / \mathrm{v})$ disks, scanning from 600 to $4000 \mathrm{~cm}^{-1}$. Melting points are uncorrected and were obtained with an MQAPF-301 melting point apparatus (Microquimica, Campinas, Brazil). Analytical thin layer chromatography was carried out on TLC plates covered with 60GF254 silica gel. Column chromatography was performed on silica gel (60-230 mesh). Solvents used as eluents were used without further purification.

\subsection{Synthesis}

2.2.1 1-(2-Nitro-4-(trifluoromethyl)phenyl)piperidine (2)

A $100 \mathrm{~mL}$ round bottom flask initially placed in an ice bath was charged with $8.60 \mathrm{~mL}(88.2 \mathrm{mmol})$ of piperidine, $4.10 \mathrm{~mL}$ of dimethylformamide (DMF), and $4.20 \mathrm{~mL}(28.7 \mathrm{mmol})$ of 1-fluoro2-nitro-4-trifluoromethyl benzene (1). The ice bath was removed and the resulting mixture was magnetically stirred at room temperature for $1.5 \mathrm{~h}$. After this time, water was added and the resulting mixture was transferred to a separatory funnel. The aqueous phase was extracted with ethyl acetate $(4 \times 80 \mathrm{~mL})$. The organic extracts were combined and the resulting organic layer was washed with brine, dried over sodium sulfate, filtered and concentrated under reduced pressure. The resulting solid was recrystallized with methanol. Compound $\mathbf{2}$ was obtained as an orange solid in $91 \%$ yield $(7.15 \mathrm{~g}, 26.1 \mathrm{mmol})$.

TLC $R_{f}=0.40$ (ethyl acetate-hexane $16: 1 \mathrm{v} / \mathrm{v}$ ). $\mathrm{mp} 50.1-50.7^{\circ} \mathrm{C}$. IR $\left(\right.$ ATR, $\left.\mathrm{cm}^{-1}\right) \bar{\nu}_{\text {max }}: 2938,2867,2827,1621,1560,1528,1493,1449$, 1386, 1323, 1297, 1260, 1233, 1211, 1149, 1115, 1080, 1064, 1021, $974,929,906,882,856,832,789,760,724,678,629,528 .{ }^{1} \mathrm{H}$ NMR $\left(300 \mathrm{MHz}, \mathrm{CDCl}_{3}\right) \delta: 1.61-1.75(\mathrm{~m}, 6 \mathrm{H}), 3.12(\mathrm{t}, 4 \mathrm{H}, J=5.3 \mathrm{~Hz}), 7.14$ $(\mathrm{d}, 1 \mathrm{H}, J=8.7 \mathrm{~Hz}), 7.60(\mathrm{dd}, 1 \mathrm{H}, J=8.7 \mathrm{~Hz}$ and $J=2.3 \mathrm{~Hz}), 8.03(\mathrm{~d}, 1 \mathrm{H}$, $J=2.3 \mathrm{~Hz}) .{ }^{13} \mathrm{C} \mathrm{NMR}\left(75 \mathrm{MHz}, \mathrm{CDCl}_{3}\right) \delta: 24.0,25.8,52.3,120.6,120.9$ $\left(q, J_{C-F}=34.1 \mathrm{~Hz}\right), 123.7\left(q, J_{C-F}=269.6 \mathrm{~Hz}\right), 124.6\left(q, J_{C-F}=4.0 \mathrm{~Hz}\right)$, $130.1\left(q, J_{C-F}=3.4 \mathrm{~Hz}\right), 139.8,148.8$. HRMS $\left(\mathrm{M}+\mathrm{H}^{+}\right)$: Calculated for $\mathrm{C}_{12} \mathrm{H}_{14} \mathrm{~F}_{3} \mathrm{~N}_{2} \mathrm{O}_{2}$, 275.1007; found: 275.0926 .

Nitro compounds $\mathbf{3}$ to $\mathbf{7}$ (Scheme 1) were synthesized using a procedure similar to that described for the preparation of compound 2. Description of experimental data that support the structures of compounds $\mathbf{3}$ to $\mathbf{7}$ can be found in the Supporting Information. 
<smiles>O=[N+]([O-])c1cc(C(F)(F)F)ccc1F</smiles>

(1)

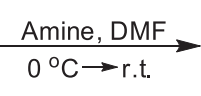<smiles>[R]c1ccc(C(F)(F)F)cc1[N+](=O)[O-]</smiles>

$(2-7)$

\begin{tabular}{llll}
\hline Compound & Amine & Yield (\%) \\
\hline $\mathbf{2}$ & piperidine & 91 \\
$\mathbf{3}$ & cyclohexylamine & 81 \\
$\mathbf{4}$ & pyrrolidine & 97 \\
$\mathbf{5}$ & diethylamine & 98 \\
$\mathbf{7}$ & morpholine & 97
\end{tabular}

Scheme 1. Synthesis of nitro compounds $\mathbf{2}$ to $\mathbf{7 .}$

\subsubsection{2-(Piperidin-1-yl)-5-(trifluoromethyl)aniline (8)}

A $50 \mathrm{~mL}$ round bottom flask initially placed in an ice bath was charged with $10.8 \mathrm{~mL}(129.6 \mathrm{mmol})$ of concentrated hydrochloric acid, $6.71 \mathrm{~g}(35.4 \mathrm{mmol})$ of tin(II) chloride, $20.0 \mathrm{~mL}$ of methanol, and $1.50 \mathrm{~g}(5.47 \mathrm{mmol})$ of 1-(2-nitro-4-(trifluoro methyl)phenyl)piperidine (2). The ice bath was removed and the resulting mixture was continuously stirred at room temperature for $42 \mathrm{~h}$. After this time, sodium hydroxide solution was added to the mixture until $\mathrm{pH}$ was approximately equal to 10 . Then, the mixture was transferred to a separatory funnel and extracted with ethyl acetate $(4 \times 80.0 \mathrm{~mL})$. The organic extracts were combined and the resulting mixture was washed with brine, dried over sodium sulfate, filtered and concentrated under reduced pressure. The residue was purified by silica gel column chromatography eluted with hexane-ethyl acetate $(11: 1 \mathrm{v} / \mathrm{v})$. Compound 8 was obtained as a white solid in $78 \%$ yield $(1.34 \mathrm{~g}, 5.49 \mathrm{mmol})$.

TLC $R_{f}=0.48$ (hexane-ethyl acetate $11: 1 \mathrm{v} / \mathrm{v}$ ). $\mathrm{mp} 50.0-50.5^{\circ} \mathrm{C}$. IR $\left(\right.$ ATR, $\left.\mathrm{cm}^{-1}\right) \bar{v}_{\text {max }}: 3452,3355,2950,2865,2805,1611,1589,1512$, $1469,1439,1379,1328,1288,1256,1227,1205,1160,1104,1064$, $936,892,860,810,745,722,663,643 .{ }^{1} \mathrm{H}$ NMR $\left(300 \mathrm{MHz} \mathrm{CDCl}_{3}\right)$ $\delta: 1.60-1.75(\mathrm{~m}, 6 \mathrm{H}), 2.88$ (brs, 4H), 4.11 (brs, $\left.2 \mathrm{H}, \mathrm{NH}_{2}\right), 6.93-7.03$ (m, 3H). ${ }^{13} \mathrm{C}$ NMR $\left(75 \mathrm{MHz}, \mathrm{CDCl}_{3}\right) \delta: 24.4,26.8,52.4,111.5$ (q, $\left.J_{C-F}=3.5 \mathrm{~Hz}\right), 115.5\left(q, J_{C-F}=4.1 \mathrm{~Hz}\right), 119.7,124.7\left(q, J_{C-F}=270.0 \mathrm{~Hz}\right)$, $126.1\left(\mathrm{q}, J_{C-F}=31.9 \mathrm{~Hz}\right), 141.7,143.4$. HRMS $\left(\mathrm{M}+\mathrm{H}^{+}\right)$: Calculated for $\mathrm{C}_{12} \mathrm{H}_{16} \mathrm{~F}_{3} \mathrm{~N}_{2}$, 245.1266; found: 245.1182.

Amines 9 to 13 (Scheme 2) were synthesized from compounds $\mathbf{3}$ to $\mathbf{7}$ using a similar procedure described for the preparation of 8. Description of experimental data that support the structures of compounds $\mathbf{9}$ to $\mathbf{1 3}$ can be found in the Supporting Information.

\subsubsection{N-(2-(Piperidin-1-yl)-5-(trifluoromethyl) phenyl) isonicotinamide (14)}

A $25 \mathrm{~mL}$ round bottom flask initially placed in an ice bath was charged with $0.629 \mathrm{~g}(3.389 \mathrm{mmol})$ of isonicotinoyl chloride hydrochloride, $0.800 \mathrm{~mL}$ of triethylamine, $8.00 \mathrm{~mL}$ of dichloromethane and $0.400 \mathrm{~g}(1.64 \mathrm{mmol})$ of 2-(piperidin-1-yl)-5(trifluoromethyl) aniline (8). The ice-bath was removed and the mixture was magnetically stirred at room temperature for $3 \mathrm{~h}$. Then, $10.0 \mathrm{~mL}$ of distilled water was added, and the mixture

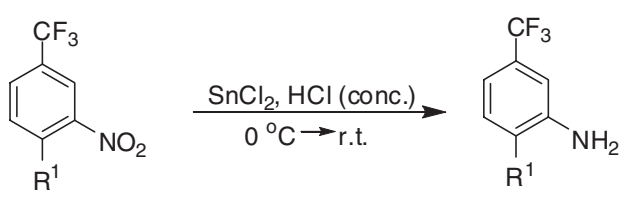

$(2-7)$

$(8-13)$

\begin{tabular}{lll}
\hline Compound & Yield (\%) \\
\hline 8 & 78 \\
11 & 56 \\
12 & 77 \\
13 & 97
\end{tabular}

Scheme 2. Synthesis of amines $\mathbf{8}$ to 13.

was transferred to a separatory funnel. The aqueous layer was extracted with ethyl acetate $(4 \times 30.0 \mathrm{~mL})$. The organic extracts were combined and the resulting organic layer was washed with brine, dried over sodium sulfate, filtered, and concentrated under reduced pressure. The residue was purified by silica gel column chromatography eluted with hexane-ethyl acetate $(3: 1 \mathrm{v} / \mathrm{v})$. The solid was further recrystallized with acetone. Compound 14 was obtained as a white solid in $75 \%$ yield ( $430 \mathrm{mg} ; 1.23 \mathrm{mmol}$ ).

TLC $R_{f}=0.13$ (hexane-ethyl acetate $3: 1 \mathrm{v} / \mathrm{v}$ ). $\mathrm{mp} 95.6-96.7^{\circ} \mathrm{C}$. IR $\left(\right.$ ATR, $\left.\mathrm{cm}^{-1}\right) \bar{v}_{\text {max }}: 3347,2945,2917,2811,1679,1611,1587,1556$, 1527, 1455, 1434, 1380, 1334, 1308, 1239, 1165, 1107, 1093, 1061, $1022,915,895,878,839,826,751,728,681,662,644 .{ }^{1} \mathrm{H}$ NMR $\left(300 \mathrm{MHz} \mathrm{CDCl}_{3}\right) \delta: 1.65-1.81(\mathrm{~m}, 6 \mathrm{H}), 2.86(\mathrm{t}, 4 \mathrm{H}, J=5.1 \mathrm{~Hz}), 7.28$ $(\mathrm{d}, 1 \mathrm{H}, J=8.4 \mathrm{~Hz}), 7.37(\mathrm{dd}, 1 \mathrm{H}, J=8.4 \mathrm{~Hz}$ and $J=1.8 \mathrm{~Hz}), 7.76(\mathrm{dd}$, $2 \mathrm{H}, J=4.5 \mathrm{~Hz}$ and $J=1.5 \mathrm{~Hz}), 8.83-8.85(\mathrm{~m}, 3 \mathrm{H}), 9.55(\mathrm{~s}, 1 \mathrm{H}, \mathrm{NH}) .{ }^{13} \mathrm{C}$ $\operatorname{NMR}\left(75 \mathrm{MHz}_{1} \mathrm{CDCl}_{3}\right) \delta: 24.0,27.1,53.8,116.6,120.8,121.1,121.6$ $\left(q, J_{C-F}=3.7 \mathrm{~Hz}\right), 124.2\left(q, J_{C-F}=270.5 \mathrm{~Hz}\right), 127.5\left(q, J_{C-F}=32.3 \mathrm{~Hz}\right)$, 
133.4, 141.8, 145.9, 151.1, 163.0. HRMS $\left(\mathrm{M}+\mathrm{H}^{+}\right)$: Calculated for $\mathrm{C}_{18} \mathrm{H}_{19} \mathrm{~F}_{3} \mathrm{~N}_{3} \mathrm{O}$, 350.1480; found: 350.1420 .

The trifluoromethyl amides $\mathbf{1 5}$ to $\mathbf{3 6}$ (Scheme 3) were prepared by using a similar methodology to that described for compound 14. Description of experimental data that support the structures of compounds $\mathbf{1 5}$ to $\mathbf{3 6}$ can be found in the Supporting Information.

\subsection{Biological assays}

Photosynthetically active thylakoid membranes were isolated from market spinach (Spinacia oleracea L.) leaves as previously described, ${ }^{11}$ with minor modifications. Briefly, $20 \mathrm{~g}$ deveined plant material was resuspended in $100 \mathrm{~mL}$ of ice-cold $20 \mathrm{mmol} \mathrm{L}^{-1}$ Tricine-NaOH buffer ( $\mathrm{pH} 8.0$ ) containing $10 \mathrm{mmol} \mathrm{L}^{-1} \mathrm{NaCl}, 5 \mathrm{mmol}$ $\mathrm{L}^{-1} \mathrm{MgCl}_{2}$ and $0.4 \mathrm{~mol} \mathrm{~L}^{-1}$ sucrose, and homogenized for $30 \mathrm{~s}$ in a blender at maximal speed. The homogenate was filtered through surgical gauze and the filtrate was centrifuged at $4{ }^{\circ} \mathrm{C}$ for $1 \mathrm{~min}$ at $500 \times g$; the supernatant was further centrifuged for $10 \mathrm{~min}$ at $1500 \times g$. Pelleted chloroplasts were osmotically swollen by resuspension in a sucrose-lacking buffer, immediately diluted 1:1 with sucrose-containing buffer, and kept on ice in the dark until used. Following dilution with $80 \%(\mathrm{v} / \mathrm{v})$ acetone, the chlorophyll content was calculated on the basis of Arnon's formula. The basal rate of photosynthetic electron transport was measured following light-driven ferricyanide reduction. Aliquots of membrane preparations corresponding to $5 \mu \mathrm{g}$ chlorophyll were incubated at $24^{\circ} \mathrm{C}$ in $0.2 \mathrm{~mL}$ cuvettes containing $20 \mathrm{mmol} \mathrm{L}^{-1}$ Tricine- $\mathrm{NaOH}$ buffer (pH 8.0), $10 \mathrm{mmol} \mathrm{L}^{-1} \mathrm{NaCl}, 5 \mathrm{mmol} \mathrm{L}^{-1} \mathrm{MgCl}_{2}, 0.2 \mathrm{~mol} \mathrm{~L}^{-1}$ sucrose and $2 \mathrm{mmol} \mathrm{L}^{-1} \mathrm{~K}_{3}\left[\mathrm{Fe}(\mathrm{CN})_{6}\right]$. The assay was initiated by exposure to saturating light $\left(800 \mu \mathrm{mol} \mathrm{m} \mathrm{m}^{-2} \mathrm{~s}^{-1}\right)$, and the rate of ferricyanide reduction was measured at 1-min intervals for 20 min against an exact blank at $420 \mathrm{~nm}$. Activity was calculated over the linear portion of the curve from a molar extinction coefficient of 1000 (mol $\left.\mathrm{L}^{-1}\right)^{-1} \mathrm{~cm}^{-1}$. Trifluoromethyl amides $\mathbf{1 4}$ to $\mathbf{3 6}$ were dissolved in DMSO at $20 \mathrm{mmol} \mathrm{L}^{-1}$; solutions were then diluted, so as to obtain $100 \times$ working solutions in DMSO. Their effect on the photosynthetic electron transport was evaluated in parallel assays in which the compounds were added to the reaction mixture to a final concentration ranging from 0.5 to $100 \mu \mathrm{mol} \mathrm{L} \mathrm{L}^{-1}$. For each dose, the assay was carried out at least in quadruplicate, and results were expressed as the percentage of controls treated with the same volume of solvent. Phosphorylating electron flow was assessed under the same conditions but in the presence of $0.5 \mathrm{mmol} \mathrm{L}^{-1}$ ADP and $2 \mathrm{mmol} \mathrm{L}^{-1} \mathrm{~K}_{2} \mathrm{HPO}_{4}$. Uncoupled activity was measured following the addition of $2 \mathrm{mmol} \mathrm{L}^{-1} \mathrm{NH}_{4} \mathrm{Cl}$ to the basal reaction mixture. In these cases, ferricyanide reduction was measured at 30 s intervals for 10 min. Reported values are mean \pm SE over replicates. The concentrations causing $50 \%$ inhibition $\left(\mathrm{IC}_{50}\right)$ and their confidence limits were estimated by nonlinear regression analysis using Prism 6 for Windows, version 6.03 (GraphPad Software, La Jolla, CA, USA).

Synechococcus elongatus, strain PCC 6301, was grown at $24 \pm 1^{\circ} \mathrm{C}$ under 14 -h days ( $150 \mu \mathrm{mol} \mathrm{m}{ }^{-2} \mathrm{~s}^{-1}$ PAR) and 10 -h nights as previously described. ${ }^{12}$ Late log-grown cells were sedimented by centrifugation $5 \mathrm{~min}$ at $4000 \times \mathrm{g}$ and used to inoculate 96-well plates, $0.2 \mathrm{~mL}$ per well, to an initial density of about $1.0 \mathrm{mg} \mathrm{L}^{-1}$ chlorophyll. Aliquots $(2 \mu \mathrm{L})$ of suitable dilutions of a given compound in DMSO were added so as to obtain final concentrations ranging from 0.5 to $200 \mu \mathrm{mol} \mathrm{L^{-1 }}$. A complete randomized design with four replications was adopted. Cell growth in each well was followed for 1 week by daily determination of absorbance using a Ledetect 96 plate reader (Labexim, Lengau, Austria) equipped with a LED plug-in at $660 \mathrm{~nm}$, subtracting turbidity at $750 \mathrm{~nm}$. Following logarithmic transformation of data, growth constants were calculated and expressed as percent of the mean value for controls (no fewer than 16 replications) treated with the same volume of DMSO. Mean values \pm SE over replicates are reported. The concentrations causing $50 \%$ inhibition $\left(\mathrm{IC}_{50}\right)$ and their confidence limits were estimated as detailed above. The effect of detergents on the inhibitory activity of selected brominated amides was evaluated by supplementing the growth medium with either sodium dodecyl sulfate (SDS) or Triton X100 at levels [160 $\mu \mathrm{mol} \mathrm{L}^{-1}(0.02 \times$ the critical micellar concentration) and $25 \mu \mathrm{mol} \mathrm{L}^{-1}(0.1 \times$ the critical micellar concentration), respectively] that had been previously shown to influence polyphosphonate uptake by the cyanobacterium Spirulina platensis strain PCC 9438 without affecting algal growth. ${ }^{13}$

\subsection{Molecular modeling and quantitative structure-activity relationship}

Compounds $\mathbf{1 4}$ to $\mathbf{3 6}$ were studied by means of molecular modeling and quantitative structure-activity relationship (QSAR). Even though the number of samples is small for a QSAR regression model, it is assumed as reasonable taking the ASTM standard practices in a spectroscopic quantitative analysis as consideration. It states that for a complex data if a multivariate model is developed using three or fewer factors, then the calibration set should contain a minimum of 24 samples. ${ }^{14}$

Molecules were modeled from crystal structures of benzanilide ${ }^{15}$ and other aryl-containing small molecules, ${ }^{16-20}$ and ligands in complexes with proteins (PDB codes $2 \mathrm{P} 16^{21}$ and $2 \mathrm{~W} 26^{22}$ ), by using WebLab ViewerPro $4.0^{23}$ and GaussView 4.1.2. ${ }^{24}$ Whenever necessary, inspection of the most stable conformers was carried out at AM1 level in Gaussian 03 W. ${ }^{25}$ Geometry optimization in Density Function Theory (DFT) calculations was carried out first at B3LYP/3-21G* and then at B3LYP/6-31G** level in Gaussian $03 \mathrm{~W}$. Then, geometry optimizations with atomic charge and spin density calculations were performed for radical anions $14^{\circ-}$ to $3^{\circ} 6^{-}$at the same DFT levels. Molecular descriptors for compounds $\mathbf{1 4}$ to $\mathbf{3 6}$ were calculated by using Gaussian 03 W, Marvin View 5.3.4 ${ }^{26}$ and Symyx Draw 3.3. ${ }^{27}$ Electron affinity (EA) was calculated as the difference between electronic energies of radical anions and their corresponding neutral species. SCORE, an integer descriptor with positive, zero or negative contributions to biological activity relative to the simplest compound $\mathbf{3 4}$, was also generated (Table S1 and Table S2 in the Supporting Information) based on a priori approach $^{28,29}$ and molecular conformations from DFT calculations. One hundred and forty-six molecular descriptors were generated. A digital filter ${ }^{30}$ was applied to identify and eliminate those descriptors that had the absolute value of Pearson correlation coefficient $(|r|)$ with the biological activity $\left(\mathrm{pIC}_{50}=-\log \left(\mathrm{IC}_{50} \mathrm{molL}^{-1}\right)\right.$ smaller than 0.5 and abnormal dispersion in scatterplots with respect to $\mathrm{plC}_{50}$. The original set of 146 descriptors was reduced to 21 . Then, the ordered predictor selection (OPS) algorithm ${ }^{31}$ was used for variable selection, and the set of five molecular descriptors obtained was used to build the final regression model by means of partial least squares (PLS). ${ }^{32}$ PLS modeling and model validation (leave-one-out and leave-many-out cross-validation, y-randomization and sign change (heck) $)^{33,34}$ was carried out by using the QSAR modeling software. ${ }^{35}$ Descriptors and the biological activity were autoscaled (column wise mean-centered and scaled to unity variance) prior to chemometric analysis. 
<smiles>Cc1ccc(C(F)(F)F)cc1N</smiles>

$\mathrm{R}^{1}$

(8-13)

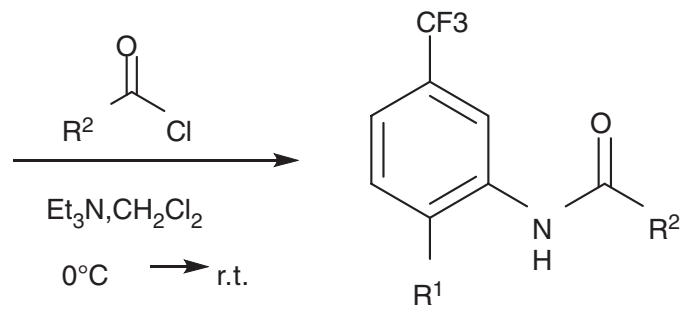

(14-36)

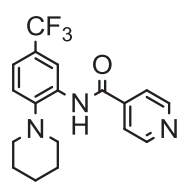

(14)

$75 \%$<smiles>O=C(Nc1cc(C(F)(F)F)ccc1NC1CCCCC1)c1ccncc1</smiles>

(15)

$82 \%$

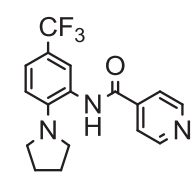

(16)

$70 \%$<smiles>CCN(CC)c1ccc(C(F)(F)F)cc1NC(=O)c1ccncc1</smiles>

(17)

$85 \%$<smiles>CC(C)(C)c1ccc(NC(=O)c2ccncc2)c(N2CCOCC2)c1</smiles>

(18)

$78 \%$<smiles>O=C(Nc1cc(C(F)(F)F)ccc1Nc1ccc(Br)cc1)c1ccncc1</smiles><smiles>O=C(Nc1cc(C(F)(F)F)ccc1N1CCCCC1)c1cccnc1Cl</smiles>

(20) $78 \%$

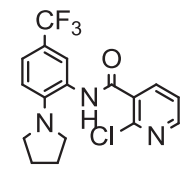

(21)<smiles>O=C(Nc1cc(C(F)(F)F)ccc1NC1CCCCC1)c1cccnc1</smiles>

(26)

$53 \%$

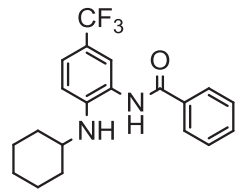

(32)

$(31)$
$88 \%$<smiles>CCN(CC)c1ccc(C(F)(F)F)cc1NC(=O)c1cccnc1Cl</smiles>

(22) $59 \%$<smiles>O=C(Nc1ccc(C(F)(F)F)cc1N1CCOCC1)c1cccnc1Cl</smiles>

$91 \%$<smiles>O=C(Nc1cccc(C(F)(F)F)c1N1CCOCC1)c1cccnc1</smiles>

(29)

$74 \%$<smiles>O=C(Nc1cc(C(F)(F)F)ccc1N1CCCC1)c1cccnc1</smiles>

(27) $73 \%$<smiles>O=C(Nc1cc(C(F)(F)F)ccc1N1CCCC1)c1cccnc1</smiles>

(28)<smiles>O=C(Nc1cc(C(F)(F)F)ccc1N1CCCC1)c1ccccc1</smiles>

(33)<smiles>CCN(CC)c1ccc(C(F)(F)F)cc1NC(=O)c1ccccc1</smiles>

(34)<smiles>O=C(Nc1cc(C(F)(F)F)ccc1N1CCOCC1)c1ccccc1</smiles>

(35)<smiles>O=C(Nc1ccc(C(F)(F)F)cc1Nc1ccc(Br)cc1)c1cccnc1Cl</smiles>

(24)

$37 \%$<smiles>O=C(Nc1cc(C(F)(F)F)ccc1Nc1ccc(Br)cc1)c1cccnc1</smiles>

(30)

Scheme 3. Preparation of trifluoromethyl amides $\mathbf{1 4}$ to 36 .

\section{RESULTS AND DISCUSSION}

\subsection{Synthesis of amides}

The trifluoromethyl amides $\mathbf{1 4}$ to $\mathbf{3 6}$ were prepared in three steps as follows. The nucleophilic aromatic substitution between commercially available 1-fluoro-2-nitro-4-trifluoromethyl benzene (1) and different amines afforded the nitro compounds $\mathbf{2}$ to $\mathbf{7}$ in $81-98 \%$ yield (Scheme 1).

Then, the reduction of nitro compounds with $\mathrm{SnCl}_{2} / \mathrm{HCl}$ afforded the amines 8 to 13 in yields ranging from 56-94\% (Scheme 2).

In the last step, the amines $\mathbf{8}$ to $\mathbf{1 3}$ were acylated via reaction with different acyl chlorides resulting in the formation of trifluoromethyl amides 14 to $\mathbf{3 6}$, as depicted in Scheme 3. Synthesis of the amides was planned so that it would be possible to assess the effects of $R^{1}$ (aliphatic, aromatic and alicyclic groups attached to nitrogen) and $R^{2}$ (phenyl and heteroaromatic groups attached to carbonyl) moieties on the biological activity. Yields for the reactions involved in the preparation of compounds $\mathbf{1 4}$ to $\mathbf{3 6}$ are also shown in Scheme 3.

The identity of all synthesized compounds was confirmed by IR and NMR $\left({ }^{1} \mathrm{H}\right.$ and $\left.{ }^{13} \mathrm{C}\right)$ spectroscopy. High-resolution mass spectrometry confirmed the molecular formula of the substances. 

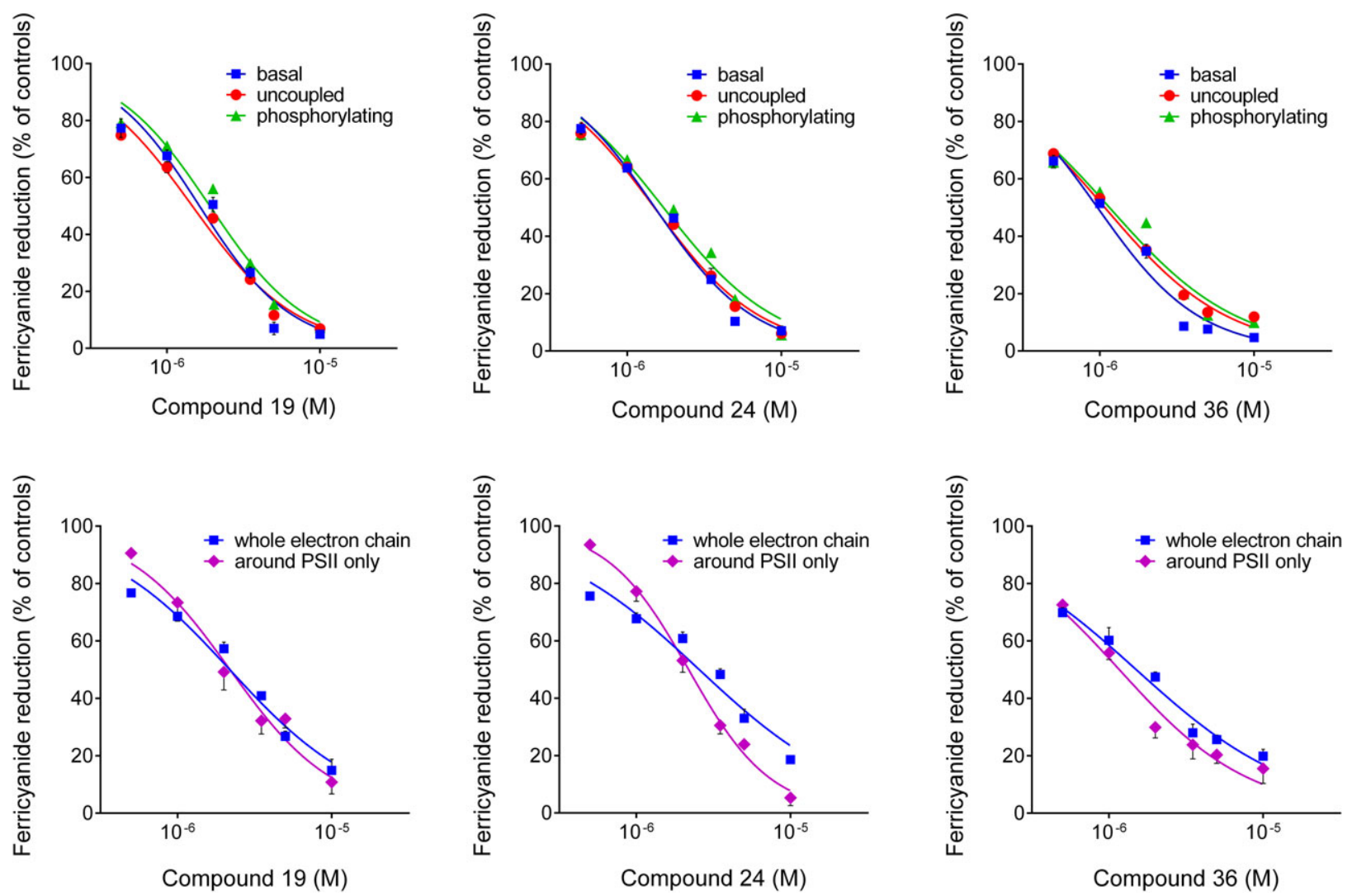

Figure 2. Upper panels: Effects of compounds 19, 24 and $\mathbf{3 6}$ on the photosynthetic electron flow under basal, uncoupling and phosphorylating conditions. Results were expressed as percentage of values obtained with untreated controls, and are means \pm SE over four replicates. Activities in controls (eight replicates) were $49.9 \pm 0.6,80.3 \pm 0.6$ and $57.7 \pm 0.9$ nkat $(\mathrm{mg} \text { chlorophyll })^{-1}$ under the three experimental conditions, respectively. Lower panels: effects of trifluoromethyl amides on ferricyanide reduction by either the whole electron transport chain or the PSIl alone. Uncoupled activity was blocked by the addition of the cytochrome b6f inhibitor DB-MIB at $2 \mu \mathrm{mol} \mathrm{L}^{-1}$, and an electronic transfer from water to ferricyanide that excludes PSI $\left(\mathrm{H}_{2} \mathrm{O} \rightarrow \mathrm{PSII} \rightarrow \mathrm{D} 1\right.$ protein $\rightarrow$ phenylenediamine $\rightarrow$ ferricyanide) was restored through the addition of $0.1 \mathrm{mmol} \mathrm{L}^{-1}$ phenylenediamine. The ability of the compounds to interfere with either transfer was evaluated. Replications were as in upper panels.

\subsection{Biological activity of trifluoromethyl amides}

As several herbicides targeting the photosynthetic apparatus possess an amide group, the effects of trifluoromethyl amides $\mathbf{1 4}$ to 36 on the chloroplastic electron transport chain were investigated by measuring the light-driven reduction of potassium ferricyanide by isolated thylakoid membranes. The results, expressed as the concentrations causing $50 \%$ inhibition $\left(\mathrm{IC}_{50}\right)$ of activity, are summarized in Table 1.

With only the exceptions of $\mathbf{2 5}$ and $\mathbf{3 2}$, all the compounds were found to inhibit the electron flow from water to potassium ferricyanide, although to a different degree. Interestingly, the most active compounds $19, \mathbf{2 4 ,} 30$ and $\mathbf{3 6}$ present a common structural feature, i.e. the presence of a $p$-bromophenyl moiety, which seems to increase remarkably the inhibitory potential of the scaffold.

In order to gain more information on the mode of action of these compounds, the activity of the three most effective inhibitors was characterized in more detail. At first, the effect of increasing concentrations of the compounds on ferricyanide reduction was evaluated under basal, uncoupling or phosphorylating conditions. The results, presented in the upper panels of Fig. 2, showed very similar patterns under all the conditions adopted. These results suggest that trifluoromethyl amides interact directly with the electron transport chain, acting as neither uncouplers nor energy transfer inhibitors. Then, ferricyanide reduction under basal conditions was blocked by the addition of the cytochrome b6f inhibitor 2,5-dibromo-3-methyl-6-isopropyl-p-benzoquinone
(DB-MIB), and an electronic transfer from water to ferricyanide that excludes PSI was restored through the addition of phenylenediamine. The ability of the selected compounds to interfere also with this transfer at comparable rates (lower panels in Fig. 2) implies that PSI is not concerned and that, as for most photosynthetic inhibitors used as herbicides, PSII is the target of their action.

Substances able to interfere with the photosynthetic electron transport chain are potentially susceptible to be endowed with biological activity against photosynthetic organisms. However, this is not obvious, since several factors, including differential membrane permeability/solubility, subcellular compartmentalization, and the occurrence of metabolization/detoxification reactions, can completely abolish inside the cell the inhibitory potential found in vitro for a given compound. To verify this, the most active inhibitors of the Hill reaction were characterized with respect to the ability to inhibit the photoautotrophic growth of a cyanobacterial model strain, Synechococcus elongatus PCC 6301. Results are summarized in Table 2.

All the compounds were able to significantly inhibit algal growth in the range tested. However, the patterns in vivo were not perfectly consistent with those in vitro, with some difference with respect to both the relative effectiveness and the inhibition slopes (Fig. 3).

Such a discrepancy might depend on either a different permeability of the compounds across the cell and the thylakoid membranes, or the ability of the cyanobacterial cell to at least 
Table 1. In vitro effects of compounds $\mathbf{1 4}$ to $\mathbf{3 6}$ on ferricyanide reduction by functionally intact chloroplasts isolated from $\mathrm{S}$. oleracea leaves $^{\text {a }}$

\begin{tabular}{|c|c|}
\hline Compound & $\mathrm{IC}_{50}\left(\mu \mathrm{mol} \mathrm{L}^{-1}\right)$ \\
\hline 14 & $26.1 \pm 4.7$ \\
\hline 15 & $93.9 \pm 13.0$ \\
\hline 16 & $30.9 \pm 3.2$ \\
\hline 17 & $63.0 \pm 8.1$ \\
\hline 18 & $213 \pm 86$ \\
\hline 19 & $1.5 \pm 0.3$ \\
\hline 20 & $13.2 \pm 1.4$ \\
\hline 21 & $124 \pm 26$ \\
\hline 22 & $19.6 \pm 4.2$ \\
\hline 23 & $85.2 \pm 16.7$ \\
\hline 24 & $1.2 \pm 0.2$ \\
\hline 25 & Ineffective $^{b}$ \\
\hline 26 & $23 \pm 3.5$ \\
\hline 27 & $210 \pm 82$ \\
\hline 28 & $76.3 \pm 7.5$ \\
\hline 29 & $245 \pm 136$ \\
\hline 30 & $4.9 \pm 0.7$ \\
\hline 31 & $107 \pm 44$ \\
\hline 32 & Ineffective ${ }^{b}$ \\
\hline 33 & $128 \pm 69$ \\
\hline 34 & $13.9 \pm 1.8$ \\
\hline 35 & Ineffective $^{\mathrm{b}}$ \\
\hline 36 & $1.1 \pm 0.3$ \\
\hline Diuron & $0.31 \pm 0.04$ \\
\hline Hexazinone & $0.15 \pm 0.03$ \\
\hline Lenacil & $0.11 \pm 0.02$ \\
\hline \multicolumn{2}{|c|}{$\begin{array}{l}\text { a Basal activity was measured in quadruplication either in the absence } \\
\text { or in the presence of a given compound at concentrations ranging } \\
\text { from } 0.5 \text { to } 100 \mu \text { mol } \mathrm{L}^{-1} \text {. Values were expressed as percentage of } \\
\left.\text { untreated controls. The concentrations causing } 50 \% \text { inhibition ( } \mathrm{IC}_{50}\right) \\
\text { and their confidence limits were estimated by nonlinear regression } \\
\text { analysis using Prism } 6 \text { for Windows, version } 6.03 \text { (GraphPad Software) } \\
\text { The effect of some reference herbicides under the same experimental } \\
\text { conditions is also reported as a term of comparison. } \\
{ }^{b} \text { Ineffective compounds presented } \mathrm{IC}_{50}>500 \mu \mathrm{mol} \mathrm{L}^{-1} \text {. }\end{array}$} \\
\hline
\end{tabular}

partially detoxify the active molecules with different efficiency. The overall lower effectiveness in vivo of these bromophenyl trifluoromethyl amides (ID ${ }_{50}$ values 1 to 2 orders of magnitude higher than those found in vitro), and the strikingly different slope of the inhibition curves obtained for compounds 19 and $\mathbf{3 0}$ with respect to those for compounds $\mathbf{2 4}$ and $\mathbf{3 6}$ (Fig. 3) seem to strengthen the former possibility. To substantiate such a hypothesis, the evaluation of the effect of these trifluoromethyl amides against cyanobacterial growth was repeated by supplementing the culture medium with either $160 \mu \mathrm{mol} \mathrm{L}^{-1}$ SDS or $25 \mu \mathrm{mol} \mathrm{L}^{-1}$ Triton $\mathrm{X} 100$. At these levels, the former detergent had indeed been found to increase the uptake of the polyphosphonate Dequest ${ }^{\circledR}$ 2054 by the cyanobacterium Spirulina platensis without affecting algal growth, whereas the latter had a detrimental effect on polyphosphonate metabolization. ${ }^{13}$ In this case, however, the inhibition curves obtained perfectly overlapped those found in the absence of detergents (data not shown).

\subsection{Quantitative structure-activity relationship analysis}

In order to gain information about the structure of amides $\mathbf{1 4}$ to 36 and the ability to interfere with the photosynthetic electron
Table 2. In vivo effects of bromophenyl trifluoromethyl amides 19, 24, $\mathbf{3 0}$ and $\mathbf{3 6}$ on the growth of the cyanobacterium Synechococcus elongatus ${ }^{\mathrm{a}}$

\begin{tabular}{lc} 
Compound & $\mathrm{IC}_{50}\left(\mu \mathrm{mol} \mathrm{L}^{-1}\right)$ \\
\hline $\mathbf{1 9}$ & $8.9 \pm 0.9$ \\
$\mathbf{2 4}$ & $110 \pm 33$ \\
$\mathbf{3 0}$ & $11.4 \pm 1.7$ \\
$\mathbf{3 6}$ & $80.8 \pm 31.2$ \\
Hexazinone & $0.35 \pm 0.02$ \\
\hline
\end{tabular}

${ }^{\text {a }}$ Algal growth was measured in quadruplication either in the absence or in the presence of a given compound at concentrations ranging from 0.5 to $200 \mu \mathrm{mol} \mathrm{L}^{-1}$. Values were expressed as percentage of untreated controls. The concentrations causing 50\% inhibition $\left(\mathrm{IC}_{50}\right)$ and their confidence limits were estimated by nonlinear regression analysis, as described. The effect under the same experimental conditions of the commercial herbicide hexazinone is also reported as a term of comparison.
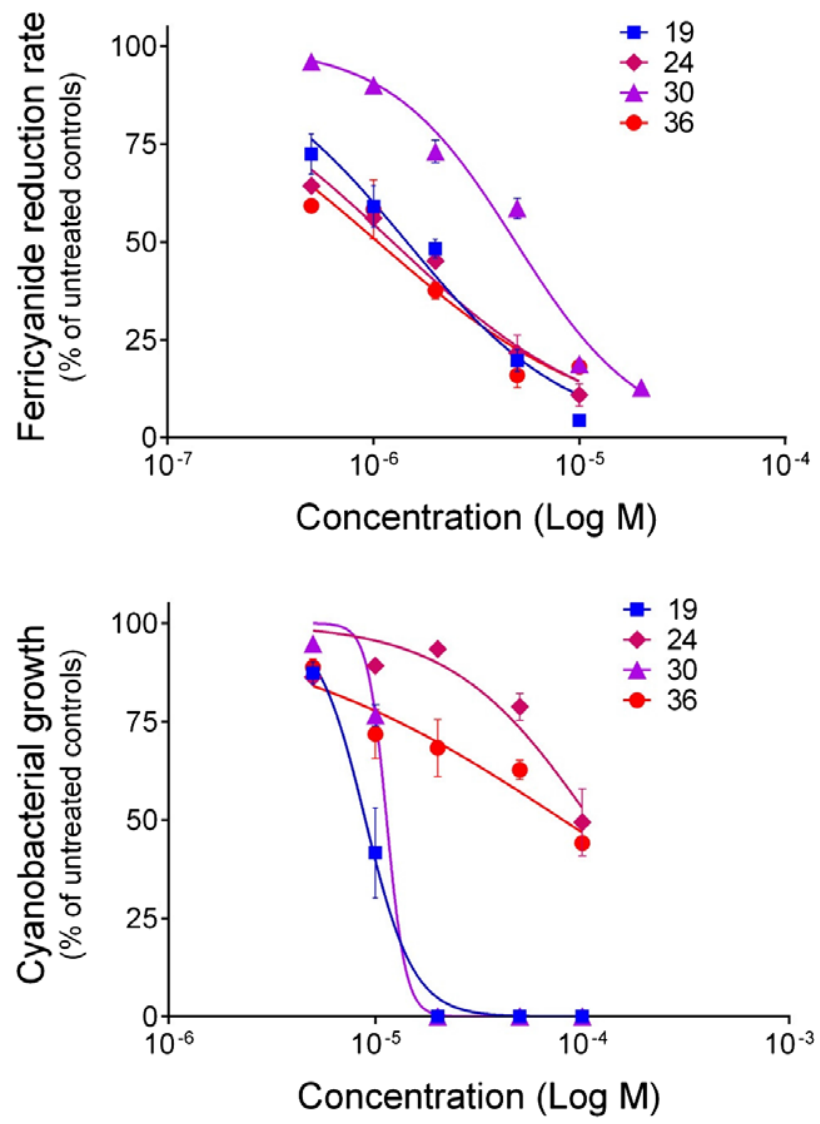

Figure 3. Comparison between the effects of compounds $\mathbf{1 9}, \mathbf{2 4 ,} \mathbf{3 0}$ and $\mathbf{3 6}$ on the photosynthetic electron flow in vitro and on cyanobacterial growth in vivo.

transport, a QSAR (quantitative structure-activity relationship) analysis was carried out. The final data set and model performance and prediction are presented in Table 3. Correlation matrix and the regression vector are shown in Table 4. The five selected descriptors are: $\mathrm{LU}_{C}$, atomic orbitals contribution to the LUMO orbital of the aromatic carbon atom having attached the $-\mathrm{CF}_{3}$ group, calculated as the sum of squares of atomic orbital coefficients for the LUMO orbital; Pol3D, Thole's molecular polarizability, 


\begin{tabular}{|c|c|c|c|c|c|c|c|c|c|}
\hline Compound & $\mathrm{LU}_{\mathrm{c}}$ & Pol3D $\left(\AA^{3}\right)$ & $w_{C}$ & $\mathrm{EA}\left(\mathrm{kcal} \mathrm{mol}{ }^{-1}\right)$ & SCORE & $\mathrm{plC}_{50, \mathrm{obs}}$ & $\mathrm{plC}_{50, \text { pred }}$ & $\Delta^{\mathrm{a}}$ & $\% \Delta^{\mathrm{b}}$ \\
\hline 14 & 0.004074 & 33.72 & 61.88 & -10.96270 & -3 & 4.583 & 4.010 & 0.573 & 12.50 \\
\hline 15 & 0.003999 & 36.25 & 62.81 & -14.26638 & -2 & 4.027 & 4.377 & -0.350 & 8.69 \\
\hline 16 & 0.003794 & 31.90 & 60.89 & -10.57778 & -2 & 4.510 & 4.095 & 0.415 & 9.20 \\
\hline 17 & 0.003630 & 32.47 & 60.53 & -11.12936 & -1 & 4.201 & 4.323 & -0.122 & 2.90 \\
\hline 18 & 0.004153 & 32.58 & 58.12 & -12.37273 & -3 & 3.672 & 4.063 & -0.391 & 10.65 \\
\hline 19 & 0.002641 & 37.83 & 52.31 & -25.56609 & 0 & 5.824 & 5.577 & 0.247 & 4.24 \\
\hline 20 & 0.004205 & 35.92 & 56.33 & -12.12735 & -2 & 4.879 & 4.461 & 0.418 & 8.57 \\
\hline 21 & 0.003880 & 34.13 & 55.22 & -11.76267 & -1 & 3.907 & 4.560 & -0.653 & 16.71 \\
\hline 22 & 0.004062 & 34.82 & 54.92 & -16.62149 & 0 & 4.708 & 4.828 & -0.120 & 2.55 \\
\hline 23 & 0.004246 & 34.80 & 52.93 & -13.51588 & -2 & 4.070 & 4.511 & -0.441 & 10.84 \\
\hline 24 & 0.002137 & 40.07 & 48.48 & -26.46852 & 1 & 5.921 & 6.091 & -0.170 & 2.87 \\
\hline 25 & 0.004952 & 33.77 & 61.88 & -6.01401 & -3 & 3.301 & 3.737 & -0.436 & 13.21 \\
\hline 26 & 0.004474 & 36.32 & 62.81 & -9.39677 & -2 & 4.638 & 4.182 & 0.456 & 9.83 \\
\hline 27 & 0.004517 & 31.96 & 60.89 & -5.60325 & -2 & 3.678 & 3.851 & -0.173 & 4.70 \\
\hline 28 & 0.005425 & 32.66 & 60.53 & -6.18473 & -1 & 4.117 & 3.888 & 0.229 & 5.56 \\
\hline 29 & 0.005028 & 32.64 & 58.12 & -7.44469 & -3 & 3.611 & 3.791 & -0.180 & 4.98 \\
\hline 30 & 0.003025 & 37.87 & 52.31 & -20.85198 & 0 & 5.310 & 5.400 & -0.090 & 1.693 \\
\hline 31 & 0.005034 & 34.50 & 65.51 & -0.52699 & -2 & 3.971 & 3.673 & 0.298 & 7.50 \\
\hline 32 & 0.004375 & 37.05 & 66.29 & -3.91981 & -1 & 3.301 & 4.156 & -0.855 & 25.90 \\
\hline 33 & 0.004405 & 32.69 & 64.66 & -0.13570 & -1 & 3.893 & 3.819 & 0.074 & 1.90 \\
\hline 34 & 0.005588 & 33.39 & 64.28 & -0.70148 & 0 & 4.857 & 3.805 & 1.052 & 21.66 \\
\hline 35 & 0.005207 & 33.37 & 61.71 & -1.95235 & -2 & 3.301 & 3.710 & -0.409 & 12.39 \\
\hline 36 & 0.003314 & 38.61 & 55.19 & -15.85260 & 1 & 5.959 & 5.332 & 0.627 & 10.52 \\
\hline
\end{tabular}

\begin{tabular}{|c|c|c|c|c|c|c|}
\hline Descriptor & Pol3D & $w_{C}$ & EA & SCORE & $\mathrm{plC}_{50, \mathrm{obs}}$ & Regr. coeff. \\
\hline $\mathrm{LU}_{\mathrm{C}}$ & -0.668 & 0.716 & 0.888 & -0.528 & -0.697 & -0.196 \\
\hline Pol3D & - & -0.522 & -0.671 & 0.618 & 0.683 & 0.193 \\
\hline$w_{C}$ & - & - & 0.866 & -0.462 & -0.627 & -0.177 \\
\hline EA & - & - & - & -0.463 & -0.728 & -0.205 \\
\hline SCORE & - & - & - & - & 0.724 & 0.204 \\
\hline
\end{tabular}

calculated for 3D molecular structure using Marvin View 5.3.426; $w_{C}$, mass percentage of the carbon content; $E A$, electron affinity; and SCORE. Measured in vitro activity $\left(\mathrm{IC}_{50}\right)$ for amides 14 to 36 (Table 1) ranges over two orders of magnitude. Descriptors mutual correlation ranges from 0.46 to 0.89 , and moderate correlations between descriptors and $\mathrm{plC}_{50}$ are within the 0.63 to 0.73 range, in terms of absolute values of Pearson correlation coefficients (Table 4).

The final PLS model has one latent variable describing $71.0 \%$ of the original information. The model's basic statistics $\left(R^{2}=0.677\right.$, $\left.Q^{2}=0.603\right)$ satisfies the minimal requirements for $\mathrm{QSAR}\left(R^{2}>0.6\right.$, $\left.Q^{2}>0.5\right) .^{33}$ Standard errors $(\mathrm{SEC}=0.473, \mathrm{SEV}=0.501)$ are somewhat above $10 \%$ of the mean value for $\mathrm{plC}_{50}$ (4.36). Table 3 shows that 13 compounds are over-predicted, 10 are under-predicted, and nine have percentage residuals above $10 \%$, among which two compounds (32 and $\mathbf{3 4}$ ) have residual somewhat greater than $20 \%$.

The model was thoroughly validated using a set of procedures suggested in the literature. ${ }^{33,34}$ The robustness of the optimized model was confirmed by leave- $N$-out cross-validation (LNO, Fig. 4). Mean values of $Q^{2}{ }_{\text {LNO }}$ oscillate around $Q^{2}{ }_{\text {LOO }}\left(Q^{2}\right.$ from leave-one-out cross-validation) within a narrow range, whilst the respective standard deviations are small for up to one third of samples taken out during the cross-validation. The possibility of chance correlation was tested using $\mathbf{y}$-randomization analysis ${ }^{33}$ (Fig. 5 and Fig. FS1 and Fig. FS2 in the Supporting Information). Comparing randomized models (i.e. models with scrambled $\mathrm{pIC}_{50}$ values) with the final QSAR model, no chance correlation is evident since their parameters satisfy minimum criteria for the absence of chance correlation ${ }^{33,36}$ : (1) $Q^{2}<0.1$ and $R^{2}<0.4$ (Fig. 4); (2) intercepts of linear regression equations in the plots $R(y a l, y)$ versus $R^{2}$ (Fig. FS1) and $R$ (yal,y) versus $Q^{2}$ (Fig. FS2) are smaller than 0.3 and 0.05 , respectively. Finally, the QSAR model was checked for sign changes. ${ }^{34}$ There is no change in sign for any descriptor since correlation and corresponding regression coefficients have the same signs (Table 4).

Comparing the regression model in this work with other QSAR models for PSII inhibitory activity published since 2010 


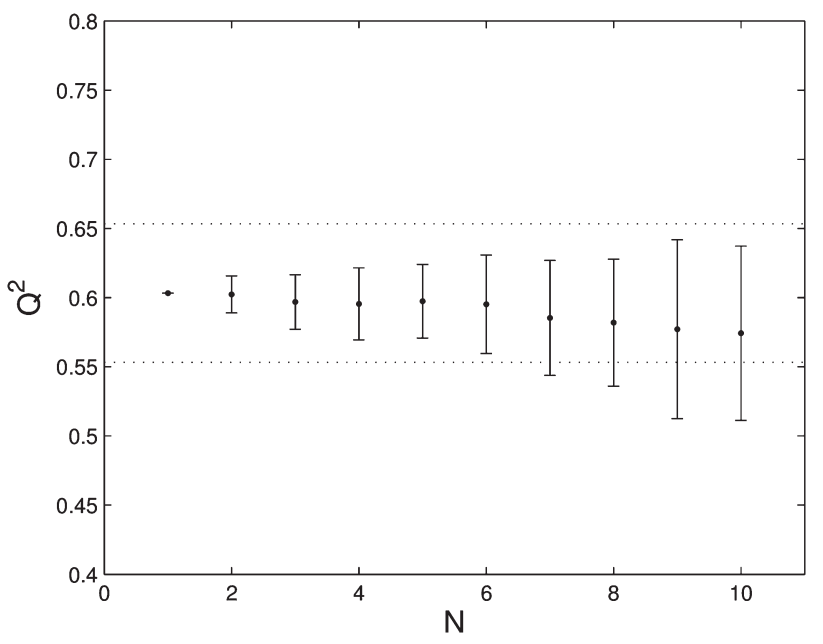

Figure 4. Performance of the final QSAR model in leave- $N$-out cross-validation (LNO, $N=1,2, \ldots, 10$ ) where the maximum block size $N$ represents a significant fraction of samples (43\%). LNO test was repeated 50 times for each value of $N$, with a randomization of all rows from the descriptors data matrix $\mathbf{X}$ and respective values of the vector $\mathbf{y}$ (vector of $\mathrm{plC}_{50}$ values) in each step of the LNO process.

(Table 5), ${ }^{37-41}$ it can be noticed that the model is of satisfactory quality. The compound set $\mathbf{1 4}$ to $\mathbf{3 6}$ is borderline for PLS in terms of the number of molecules; that is the reason data splitting-based model validations (external validation, bootstrapping) were not applied. However, the reported literature models in the period 2010-2014 vary from those with too few compounds and without any validation ${ }^{38}$ to those tested with external validation and being overfitted $^{37}$ or checked with bootstrap-like validations ${ }^{39,40}$ in spite of having insufficient compounds, whilst $\mathbf{y}$-randomization, LNO and sign change check have not been performed. The most recent model published in $2017^{41}$ is fair, presenting the largest number of compounds (43) among the reported models for PSII inhibitory activity. In this case, several model validations were applied, avoiding the use of data compression-based regressions like PLS.

According to the biological assays herein described, the most active compounds are 19, 24, 30 and $36\left(I_{50}\right.$ values ranging from 1 to $5 \mu \mathrm{mol} \mathrm{L^{-1 }}$ or $5.3-6.0$ in plC $_{50}$ units, Table 1). The predicted activity values range from 5.4 to 6.1 in plC p $_{50}$ units (Table 3 ). These values are smaller but still comparable to inhibitory activities of well-known herbicides such as atrazine $\left(0.23 \mu \mathrm{mol} \mathrm{L^{-1 }}\right.$ or 6.6 in plC $_{50}$ units as an average from two studies), ${ }^{42,43}$ diuron $\left(0.27 \mu \mathrm{mol} \mathrm{L} \mathrm{L}^{-1}\right.$ or 6.6 in $\mathrm{plC}_{50}$ units $){ }^{11}$ and the atrazine derivative TPA (1-trifuoromethyl-3-methyl-5-[4-trifluoromethyphenyl]

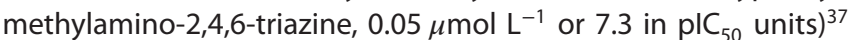
as determined in similar bioassays employing $S$. oleracea chloroplasts.

\subsection{Chemistry of the QSAR model}

The five selected descriptors of the QSAR model, namely $L_{C}$, Pol3D, $w_{C}, E A$ and SCORE, have regression coefficients of considerable size (absolute values range from 0.18 to 0.20 , Table 4). Only SCORE and Pol3D have positive regression coefficients. Molecular descriptors may indicate molecular features of good PSII inhibitors: reactivity, conformational features, and intermolecular interactions with the receptor. Trifluoromethyl aryl amides $\mathbf{1 4}$ to $\mathbf{3 6}$ most likely act similar to many herbicides, which are known from the literature as displacers of plastoquinone- 9 (PQ-9) at the $Q_{B}$ active site. ${ }^{44}$

The descriptor SCORE provides important contribution to the QSAR model due to its complex nature - steric, electronic, hydrogen bonding and lipophilicity features (Table S1 and Table S2 in the Supporting Information) relative to the simplest compound $\mathbf{3 4}$. In vitro activity increases with the more positive values of SCORE, reaching non-negative values for the most active compounds (19, 24, 30 and 36) and two somewhat less active (22 and 34). In other words, good PSII inhibitors have flat and longer groups (or at least a group that does not occupy too much space), mainly hydrophobic, attached to the amine functionality $[-\mathrm{N}(\mathrm{H})-\mathrm{R}]$. In the case of the most active compounds, R corresponds to the $p$-bromophenyl group. This group, due to essential non-planarity, rigidity and branching of molecules $\mathbf{1 4}$ to $\mathbf{3 6}$, is probably placed in a predominantly hydrophobic environment at the active site (a sub-pocket or a small pocket). SCORE incorporates two more positive contributions to $\mathrm{plC}_{50}$ : (1) the aryl group attached to the nitrogen in the amide portion is phenyl or pyridinyl with ortho-chlorine, whilst other aryl types have negative contribution, meaning that the presence/absence and orientation of heteroatoms mainly define interactions with the receptor; (2) intramolecular hydrogen bond established between the amine - $\mathrm{N}(\mathrm{H})$ - portion and the carbonyl group (for compounds 15, 26 and 32) stabilizes molecular conformation and indicates possible stronger bond to the receptor.

Polarizability descriptor Pol3D is positively correlated to in vitro activity. It can be observed from molecular structures (Scheme 3) and Pol3D values (Table 3 ) that molecular polarizability increases by introducing halogen atoms $(\mathrm{Br}, \mathrm{Cl})$ and flexible ring groups (phenyl, cyclohexyl) into amine $-\mathrm{N}(\mathrm{H})$ - R portion, reaching values above $36 \AA^{3}$. In general, molecular polarizability of a ligand means its ability for charge redistribution in the external field of a receptor during the formation of receptor-ligand complex. ${ }^{45}$ The most active compounds 19, 24, 30 and 36 have a $p$-bromophenyl in the substituted amine portion, whilst the additional chlorine in the aryl amide moiety has no significance in compound 24. The $p$-bromophenyl, besides being an electron-rich and flat substituent, is also the longest substituent in topological sense (having five bonds from - $\mathrm{NH}-$ group to the terminal bromine) within the series of compounds $\mathbf{1 4}$ to $\mathbf{3 6}$, which makes this substituent suitable for increasing molecular polarizability and thus, enhancing formation of complexes of trifluoromethyl aryl amides with PSII.

Descriptor $w_{C}$ has a negative contribution to the model: molecules with higher content of carbon atoms are weaker PSII inhibitors or, alternatively, molecules with higher content of heteroatoms (halogens, nitrogen, and oxygen) are better PSII inhibitors. The most active compounds 19, 24, 30 and 36 are among those with the lowest percentage of carbon atom (48-55\%). Other chlorinated compounds (20-23) have also low carbon content (52-56\%). Higher content of carbon atoms or lower content of heteroatoms means more hydrophobic inhibitor molecules, which are not favored at the $Q_{B}$ active site of PSII. Heteroatoms in compounds $\mathbf{1 4}$ to $\mathbf{3 6}$ are able to establish strong hydrogen bonds $(\mathrm{N}, \mathrm{O})$ and other polar interactions $(\mathrm{N}$, $\mathrm{O}, \mathrm{F}, \mathrm{Br}, \mathrm{Cl}$ ) with the receptor, increase molecular polarizability and solubility, and affect electron delocalization in the aromatic rings.

Electron affinity (EA) is negatively correlated to in vitro activity. More negative values of EA indicate more stabilized radical anions, or stronger ability of neutral molecules to absorb an electron. All amides $\mathbf{1 4}$ to $\mathbf{3 6}$ are electron acceptors because of their 
Table 5. Comparison of the final QSAR model with other recent QSAR models for PSII inhibitors

\begin{tabular}{|c|c|c|c|c|c|c|}
\hline Compounds & No. & $\operatorname{Model}(s)^{a}$ & $R^{2}$ & $Q^{2}$ & Validation $^{\mathrm{b}}$ & Reference \\
\hline $14-36$ & 23 & QSAR/PLS & 0.68 & 0.60 & LOO, LNO, yrd, scc & This work \\
\hline Triazines & 38 & 3D-QSAR/ PLS & $0.92,0.95$ & $0.68,0.63$ & LOO, extv & Zhang et al. ${ }^{37}$ \\
\hline Pheny aryl amides & 12 & QSAR/MLR & $0.32-0.60$ & - & - & Dolezal et al. ${ }^{38}$ \\
\hline Fluoroalkyl nitrobenzenes & 31 & QSAR/MLR & $0.86-0.89$ & $0.70-0.81$ & blv & Karacan et al. ${ }^{39}$ \\
\hline Nostoclides & 19 & QSAR/MLR & 0.83 & 0.72 & blv & Teixeira et al..$^{40}$ \\
\hline Fused heterocyclic herbicides & 43 & QSAR/MLR & 0.77 & 0.67 & LOO, LNO, extv, yrd, r2m & Funar-Timofei et al. ${ }^{41}$ \\
\hline
\end{tabular}

${ }^{a}$ QSAR regression models: PLS, partial least squares regression; MLR, multiple linear regression.

b Model validations: LOO, leave-one-out cross-validation; LNO, leave- $N$-out cross-validation; yrd, y-randomization; scc, sign change check; extv, external validation; blv, bootstrap-like validation; $r 2 \mathrm{~m}, r^{2}{ }_{m}$ metrics.

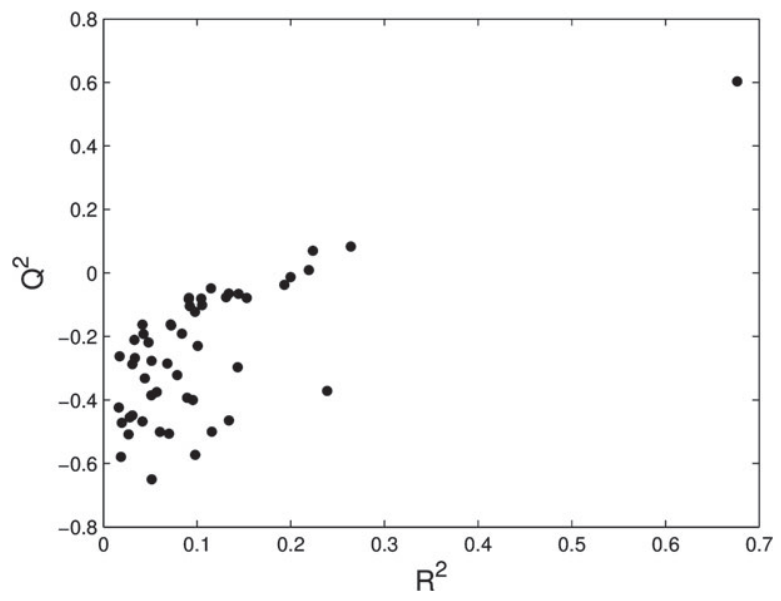

Figure 5. Performance of the final QSAR model in y-randomization: $R^{2}$ vs. $Q^{2}$ plot. In this procedure the vector $\mathbf{y}$ (vector of $\mathrm{plC}_{50}$ values) was scrambled 50 times, and each time correlations between the original $y$ and scrambled $\mathbf{y}$ were calculated as absolute values of Pearson correlation coefficients $R(\mathrm{yal}, \mathrm{y})$, regression models were built and respective coefficients of multiple determination $\left(R^{2}\right)$ and leave-one-out cross-validation $\left(Q^{2}\right)$ were determined. These randomized models, i.e. models with randomized vector $\mathbf{y}$, are shown in the plot in the region at $Q^{2}<0.1$ and $R^{2}<0.3$, and the QSAR model is placed at the right upper corner.

EA negative values (Table 3), but they differ significantly with respect to their chemical structure (Scheme 3 ) and molecular mass (correlation to EA is -0.84). The absorbed electron is easier distributed over large molecular structures or structures containing heteroatoms. That is the reason the most active molecules have the lowest EA within their groups, and besides, these molecules possess three $\pi$-electron systems, which are electron acceptors (aryl amide moiety, trifluoromethylphenyl, and p-bromophenyl). Compounds $\mathbf{2 0}$ to $\mathbf{2 4}$ posses a chlorine atom at the 3-pyridinyl ring of aryl amide portion, thus having the most negative EA ( -12 to $\left.-26 \mathrm{kcal} \mathrm{mol}^{-1}\right)$, whilst chlorine is absent at 4-pyridinyl ring in $\mathbf{1 4}$ to 19 (EA ranges from -11 to $-26 \mathrm{kcal} \mathrm{mol}^{-1}$ ). Molecules 25 to $\mathbf{3 0}$ have a 3-pyridinyl ring and even less negative EA ( -6 to $-21 \mathrm{kcal}$ $\mathrm{mol}^{-1}$ ). The weakest electron acceptors are molecules 31 to 36 presenting a phenyl ring in the aryl amide moiety (EA varies from -0.1 to $-16 \mathrm{kcal} \mathrm{mol}^{-1}$ ).

In order to identify reactive groups of compounds 14 to $\mathbf{3 6}$, selected electronic features for highly active 19 and inactive $\mathbf{2 5}$ and their radical anions $19^{\circ-}$ and $\mathbf{2 5}^{\circ-}$ were analyzed and the results are presented in Table 6 . Absorption of one electron by neutral molecules 19 and 25 results in significant molecular volume increase, electron redistribution, and the appearance of non-zero spin density. According to the sums of charges of non-hydrogen atoms $\left(\sum Q\right)$, it can be noticed that negative charge in both compounds $\mathbf{1 9}$ and $\mathbf{2 5}$ is concentrated in the aryl amide moiety and in the amine portion, whilst trifluoromethylphenyl moiety is positively charged. Upon electron absorption, the negative charge is increased by -0.7 in the aryl amide of $19^{\circ-}$ and $\mathbf{2 5}^{\mathbf{}-}$. The radicals, however, differ in distribution of the remaining negative charge: in both $19^{\circ-}$ and $\mathbf{2 5}^{\circ-}$ the trifluoromethylphenyl moiety becomes less positively charged by -0.2 , but the amine functionality becomes more negatively charged in $19^{\circ-}$ and less negatively charged in $\mathbf{2 5}^{\mathbf{}-}$. Analyzing the sum of spin densities at non-hydrogen atoms $\left(\sum S\right)$, it is clear that the three molecular fragments can be well distinguished in radicals $19^{\circ-}$ and $25^{\circ-}$ : $90 \%$ of spin density is contained in the aryl amide moiety (more precisely, in the aromatic ring conjugated with the carbonyl group), around $9 \%$ is in the trifluoromethylphenyl portion, and only about $1 \%$ of spin density is distributed in the amine functionality. The carbonyl group contains $39 \%$ and $36 \%$ of spin density in $19^{\circ-}$ and $\mathbf{2 5}^{\circ}-$, respectively. There is no essential difference between the two radical anions in spin density distribution, but there is a difference in charge distribution after electron uptake. It is presumed that similar trends are valid for the whole molecular set 14 to $\mathbf{3 6}$, once the amine moiety is the most variable molecular fragment and it contains only a minor portion of spin density.

The carbonyl seems to be a reactive, good electron-accepting group, which might be reduced by PSII. Funar-Timofei et al. ${ }^{41}$ have recently shown, by using docking analysis, that the most active herbicides may be placed at the $Q_{B}$ active site of PSII, to interact with His215 via hydrogen bond, by which the herbicide can accept a photoelectron and become a radical anion. Compounds 14 to 36 could be placed similarly, loading aryl amide with trifluoromethylphenyl at the active site, and positioning the carbonyl group in hydrogen bonding interaction with His215. The third molecular fragment, the amine, needs a subpocket or a small new pocket in the vicinity of His215. Therefore, this molecular fragment and trifluoromethylphenyl could be considered fixing fragments and aryl amide the reactive molecular fragment. The amine portion has double role considering interactions with PSII: the fixing function and defining the molecular polarizability. Atrazine ${ }^{46}$ and bromoxynil ${ }^{44}$ are well known pesticides forming hydrogen bonding with His215 when docked to PSII.

$\mathrm{LU}_{\mathrm{C}}$ is an interesting local LUMO descriptor, which is negatively correlated to the in vitro activity. This descriptor accounts for the influence of structural changes in the amine and aryl amide portions on the central phenyl ring, and for inductive effects of the 


\begin{tabular}{|c|c|c|c|c|c|c|c|c|}
\hline \multirow[b]{2}{*}{ Species } & \multicolumn{2}{|c|}{ Aryl amide } & \multicolumn{2}{|c|}{$\mathrm{CF}_{3}$-phenyl } & \multicolumn{2}{|c|}{ Subst. amine } & \multirow[b]{2}{*}{$\% \Delta V^{a}$} & \multirow[b]{2}{*}{ Unpaired electron main location ${ }^{b}$} \\
\hline & $\sum Q^{c}$ & $\sum S^{d}$ & $\sum Q^{c}$ & $\sum S^{d}$ & $\sum Q^{c}$ & $\sum S^{d}$ & & \\
\hline 19 & -0.302 & - & 0.494 & - & -0.192 & - & 0 & - \\
\hline $19^{\circ-}$ & -0.992 & 0.903 & 0.285 & 0.091 & -0.293 & 0.005 & 0.44 & Aromatic ring, $\mathrm{CO}$ \\
\hline 25 & -0.290 & - & 0.436 & - & -0.416 & - & 0 & - \\
\hline $25^{\circ-}$ & -1.030 & 0.903 & 0.250 & 0.087 & -0.220 & 0.010 & 0.48 & Aromatic ring, $\mathrm{CO}$ \\
\hline \multicolumn{9}{|c|}{$\begin{array}{l}\text { a Molecular volume increase of a species relative to the molecular volume of its parent non-radical species, expressed as percentage. } \\
\text { b Molecular fragments with the highest spin density values. } \\
\text { c Sum of Mulliken atomic charges }\left(\sum Q\right) \text {. } \\
\text { d Sum of spin densities }\left(\sum S\right) \text {. }\end{array}$} \\
\hline
\end{tabular}

trifluoromethyl group within this ring. $\mathrm{LU}_{\mathrm{C}}$ is a good 'sensor' for all these variations. No other descriptors of this kind, related to frontier molecular orbitals, have shown significant correlation to in vitro activity. It is reasonable to expect that a part of the central molecular fragment (trifluoromethylphenyl ring) would be the place where various effects of structural changes in compounds 14 to $\mathbf{3 6}$ would encounter. Trifluoromethyl group is known to be important for radical stabilization by its electron-withdrawal ability. ${ }^{47,48}$ For example, the negative charge increase for $-\mathrm{CF}_{3}$ after electron uptake was noticed to be -0.06 in $\mathbf{1 9}^{\circ-}$ and $\mathbf{2 5}^{\circ-}$. The $-\mathrm{CF}_{3}$ group is also important for stabilization of molecular complexes via various intermolecular interactions. ${ }^{49,50}$ The trifluoromethyl of atrazine derivative TPA presents intermolecular interactions with the active site $Q_{B}$ of $P S I I .{ }^{37} L_{C}$ may also encode changes in the $-\mathrm{CF}_{3}$ group during formation of ligand-receptor complex and posterior photoelectron uptake.

\section{CONCLUSION}

Several trifluoromethyl amides were synthesized in satisfactory yields through a three-step procedure. Their evaluation in vitro showed that 20 compounds out of 23 were able to interfere with the photosynthetic electron transport chain in the micromolar to millimolar range. The compounds containing a 4-bromophenyl moiety were found the most effective, with $I C_{50}$ values near

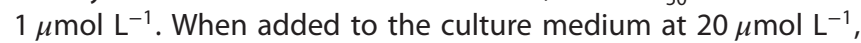
two of these derivatives were capable of completely suppressing cyanobacterial growth. Indeed, the four compounds with a long and flat 4-bromophenyl moiety were found also the most active in the QSAR study. Chemical interpretation of the QSAR model confirms its statistical validity and gives more insight into modeling more potent PSII inhibitors. Molecular descriptors indicate the importance of aromatic fragments and heteroatoms in molecular structure of effective PSII inhibitors. Trifluoromethyl amides may thus represent a novel scaffold to be exploited aiming at the development of new active ingredients for weed control. Work is currently in progress in our laboratories to both investigate further their mode of action, and to synthesize new phenyl derivatives with increased effectiveness.

\section{ACKNOWLEDGEMENTS}

The authors are grateful to the following Brazilian agencies: Coordenação de Aperfeiçoamento de Pessoal de Nível Superior (CAPES) for research fellowships; Fundação de Amparo a Pesquisa de Minas Gerais (FAPEMIG); Conselho Nacional de Desenvolvimento Científico e Tecnológico - CNPq-for research grant number 448562/2014-6 (R.R.T.). Support from the University of Ferrara (FAR 2014) is also acknowledged.

\section{SUPPORTING INFORMATION}

Supporting information may be found in the online version of this article.

\section{REFERENCES}

1 Rutherford WA and Faller $\mathrm{P}$, The heart of photosynthesis in glorious 3D. Trends Biochem Sci 26:341-344 (2004).

2 Blankenship RE and Hartman $\mathrm{H}$, The origin and evolution of oxygenic photosynthesis. Trends Biochem Sci 23:94-97 (1998).

3 Nelson $\mathrm{N}$ and Ben-Shen $\mathrm{A}$, The complex architecture of oxygenic photosynthesis. Nat Rev Mol Cell Biol 5:1 - 12 (2004).

4 Draber W, Tietjen K, Kluth JF and Trebst A. Herbicides in photosynthesis research. Angew Chem Int Ed 30:1621 - 1633 (1994).

5 Hess FD, Light-dependent herbicides: an overview. Weed Sci 48:160-170 (2000).

6 Teixeira RR, Maia AFS, Pereira WL, Lima AMA and Forlani G, Natural products and their synthetic analogues as new active principles targeting the photosynthetic machinery, in Photosynthesis: Functional Genomics, Physiological Process and Environmental Issues, ed. by Kham N. nova Science Publishers, New York, pp. 231-256 (2015).

7 Teixeira RR, Pereira WL and Pereira JL, Photosynthetic inhibitors, in Applied Photosynthesis, ed. by Najafpour MM. InTech - Open Access Publisher, Rijeka, Croatia, pp. 3-22 (2012).

8 Fuerst PE and Norman MA, Interactions of herbicides with photosynthetic electron transport. Weed Sci 39:458-464 (1991).

9 Ware GW, The Pesticide Book, 5th edition. Thomson Publications, Fresno, CA, pp. 109-132 (2000).

10 Bowyer JR, Camilleri P and Vermass WFJ, Photosystem II and its interaction with herbicides, in Herbicides (Topics in Photosynthesis), vol. 10, ed. by Baker NR and Percival MP. Elsevier, Amsterdam, pp. 27-85 (1991).

11 Vicentini CB, Mares D, Tartari A, Manfrini M and Forlani G, Synthesis of pyrazole derivatives and their evaluation as photosynthetic electron transport inhibitors. J Agric Food Chem 52:1898-1906 (2004).

12 Teixeira RR, Pereira WL, Tomaz DC, Oliveira FM, Giberti, S and Forlani G, Synthetic analogs of the natural compound cryphonectric acid interfere with photosynthetic machinery through two different mechanisms. J Agric Food Chem 61:5540-5549 (2013).

13 Forlani G, Bertazzini M, Giberti S, Wieczorek D, Kafarski $P$ and Lipok J, Sublethal detergent concentrations increase metabolization of recalcitrant polyphosphonates by the cyanobacterium Spirulina platensis. Environ Sci Pollut Res 20:3263-3270 (2013).

14 American Society for Testing and Materials (ASTM), ASTM E1655-05(2012). Standard practices for infrared multivariate quantitative analysis. ASTM International, West Conshohocken, PA (2012).

15 Bowes KF, Glidewell C, Low JN, Skakle JMS and Wardell JL, A triclinic polymorph of benzanilide: disordered molecules form hydrogenbonded chain. Acta Cryst C59:01-03 (2003). 
16 Venugopala, KN, Nayak SK and Odhav B, 2-(4-Bromoanilino)-6-(4chlorophenyl)-5-methoxycarbonyl-4-methyl-3,6-dihydropyrimidin1-ium chloride. Acta Cryst E69:0518-0519 (2013).

17 Lynch DE and McClenaghan I, 1-(4-Chlorophenylsulfanyl)-2-nitro-4(trifluoromethyl)benzene and 1-(4-chlorophenylsulfanyl)-4-nitro-2(trifluoromethyl)benzene. Acta Cryst C59:0641 - 0643 (2003).

18 Evain, M, Quillard S, Corraze B, Wang W and MacDiarmid AG, A phenyl-end-capped tetramer of aniline. Acta Cryst E58:0343-0344 (2002).

19 Gong L and Lu L, 4-[(2-Chloro-4-nitrophenyl)diazenyl]-N,Ndiethylaniline. Acta Cryst E67:0662 (2011).

20 Yanes C, Torres M, López-Rodríguez M, Núñez P and Brito I, N-(5-Nitro-2pyrrolidinylphenyl)trifluoroacetamide. Acta Cryst C53:492-493 (1997).

21 Pinto DJ, Orwat MJ, Koch S, Rossi KA, Alexander RS, Smallwood A etal., Discovery of 1-(4-methoxyphenyl)-7-oxo-6-(4-(2oxopiperidin-1-yl)phenyl)-4,5,6,7-tetrahydro-1H-pyrazolo[3,4-c] pyridine-3-carboxamide (apixaban, BMS-562247), a highly potent, selective, efficacious, and orally bioavailable inhibitor of blood coagulation factor Xa. J Med Chem 50:5339-5356 (2007).

22 Roehrig S, Straub A, Pohlmann J, Lampe T, Pernerstorfer J, Schlemmer $\mathrm{K}$ etal., Discovery of the novel antithrombotic agent 5-chloro- $N$-(\{(5S)-2-oxo-3-[4-(3-oxomorpholin-4-yl)phenyl]-1,3oxazolidin-5-yl\}methyl)thiophene-2-carboxamide (BAY 59-7939): an oral, direct factor Xa inhibitor. J Med Chem 48:5900-5908 (2005).

23 WebLab ViewerPro 4.0. Molecular Simulations, Inc., San Diego, CA (2000).

24 GaussView 4.1.2. Gaussian, Inc., Wallingford, CT (2006).

25 Frisch MJ, Trucks GW, Schlegel HB, Scuseria GE, Robb MA, Cheeseman JR et al. Gaussian 03W, version 6.1, Revision E.01. Gaussian, Inc., Wallingford, CT (2004).

26 Marvin View 5.3.4. ChemAxon Ltd., Budapest (2010).

27 Symyx Draw 3.3. Symyx Solutions, Inc.; Santa Clara, CA (2010).

28 Kiralj R and Ferreira MMC, A priori molecular descriptors in QSAR: a case of HIV-1 protease inhibitors. I. The chemometric approach. JMol Graph Model 21:435-448 (2003).

29 Kiralj R, Takahata Y and Ferreira MMC, QSAR of progestogens: Use of $a$ priori and computed molecular descriptors and molecular graphics. QSAR Comb Sci 22:430-448 (2003).

30 Barbosa EG and Ferreira MMC. Digital filters for molecular interaction field descriptors. Mol Inf 31:75-84 (2012).

31 Teófilo RF, Martins JPA and Ferreira MMC, Sorting variables by using informative vectors as a strategy for feature selection in multivariate regression. J Chemom 23:32-48 (2009).

32 Ferreira MMC, Multivariate QSAR. J Braz Chem Soc 13:742- 745 (2002).

33 Kiralj $\mathrm{R}$ and Ferreira MMC, Basic validation procedures for regression models in QSAR and QSPR studies: theory and applications. J Braz Chem Soc 20:770-787 (2009).

34 Kiralj R and Ferreira MMC, Is your QSAR/QSPR descriptor real or trash? J Chemom 24:681-693 (2010)

35 Martins JPA and Ferreira MMC, QSAR modeling: a new open source computational package to generate and validate QSAR models. Quim Nova 36:554-560 (2013).
36 Eriksson L, Jaworska J, Worth AP, Cronin MTD and McDowell RM, Methods for reliability and uncertainty assessment and for applicability of classification- and regression-based QSARs. Environ Health Perspect 111:1361-1375 (2003).

37 Zhang C, Chang S, Tian X and Tian Y, 3D-QSAR and docking modeling study of 1,3,5-triazine derivatives as PSIl electron transport inhibitor. Asian J Chem 26:264-268 (2014).

38 Dolezal M, Zitko J, Osicka Z, Kunes J, Vejsova M, Buchta V et al., Synthesis, antimycobacterial, antifungal and photosynthesis-inhibiting activity of chlorinated $N$-phenylpyrazine-2-carboxamides. Molecules 15:8567-8581 (2010).

39 Karacan MS, Yakan Ç, Yakan M, Karacan N, Zharmukhamedov SK, Shitov A etal., Quantitative structure-activity relationship analysis of perfluoroiso-propyldinitrobenzene derivatives known as photosystem II electron transfer inhibitors. Biochim Biophys Acta 1817:1229-1236 (2012).

40 Teixeira RR, Pinheiro PF, Barbosa LCA, Carneiro JWM and Forlani G, QSAR modeling of photosynthesis-inhibiting nostoclide derivatives. Pest Manag Sci 66:196-202 (2010).

41 Funar-Timofei S, Borota A and Crisan L, Combined molecular docking and QSAR study of fused heterocyclic herbicide inhibitors of D1 protein in photosystem II of plants. Mol Divers doi:https://doi.org/10 .1007/s11030-017-9735-x (2017).

42 Fujimori A, Ikeda Y, Okano R, Hiraki M, van Rensen JJS, Böger P et al., Synthesis and inhibitory effect on photosynthetic electron transport of 1,3,5-triazinylcarboxylic acid derivatives. J Pestic Sci 30:39-43 (2000).

43 Kotaka E, Ohki S, Kuboyama N, Ohki A, Koizumi K, Kohno H et al., Photosynthetic electron transport inhibitory and herbicidal activities of 2-(N-acylbenzylamino)-4-methyl-6-fluoroalkyl-1,3,5-triazine derivatives. J Pestic Sci 26:257-260 (2001).

44 Takahashi R, Hasegawa K, Takano A and Noguchi T, Structures and binding sites of phenolic herbicides in the $Q_{B}$ pocket of photosystem II. Biochemistry 49:5445-5454 (2010).

45 Andrews PR, Drug-receptor interactions, in 3D QSAR in Drug Design: Theory, Methods and Applications, ed. by Kubinyi H. Kluwer/Escom, Dordrecht, pp. 13-40 (2000).

46 Lambreva MD, Russo D, Polticelli F, Scognamiglio V, Antonacci A, Zobnina $V$ etal., Structure/function/dynamics of photosystem II plastoquinone binding sites. Curr Protein Pept Sci 15:285-295 (2014).

47 Song MG and Sheridan RS, Effects of $\mathrm{CF}_{3}$ groups and charged substituents on singlet carbene stabilities-a density functional theory study. J Phys Org Chem 24:889-893 (2011).

48 Studer A, A "renaissance" in radical trifluoromethylation. Angew Chem Int Ed 51:8950-8958 (2012).

49 Panini P and Chopra D, Experimental and computational insights into the nature of weak intermolecular interactions in trifluoromethylsubstituted isomeric crystalline $N$-methyl- $N$-phenylbenzamides. New J Chem 39:8720-8738 (2015)

50 Panini $\mathrm{P}$ and Chopra D, Understanding of noncovalent interactions involving organic fluorine, in Hydrogen Bonded Supramolecular Structures, ed. by Li Z and Wu L. Springer-Verlag, Berlin, pp. 37-67 (2015). 